$1-2002$

\title{
Doing Good Science Without Sacrificing Good Values: Why the Heuristic Paradigm is the Best Choice for Social Work
}

Jessica Heineman-Pieper

University of Chicago, jhpieper@uchicago.edu

Katherine Tyson McCrea

Loyola University Chicago, ktyson@luc.edu

Martha Heineman Pieper

Smart Love Family Services

Follow this and additional works at: https://ecommons.luc.edu/socialwork_facpubs

Part of the Social Work Commons

\section{Recommended Citation}

Heineman-Pieper, Jessica, Katherine Tyson McCrea, Martha Heineman Pieper. "Doing Good Science Without Sacrificing Good Values: Why the Heuristic Paradigm is the Best Choice for Social Work." Families in Society vol. 83, no. 1 (2002): 15-28.

This Article is brought to you for free and open access by the Faculty Publications and Other Works by Department at Loyola eCommons. It has been accepted for inclusion in Social Work: School of Social Work Faculty Publications and Other Works by an authorized administrator of Loyola eCommons. For more information, please contact ecommons@luc.edu. c) (†) $\odot$

This work is licensed under a Creative Commons Attribution-Noncommercial-No Derivative Works 3.0 License. (C) 2002 Families International, Inc. 


\title{
Doing Good Science Without Sacrificing Good Values: Why the Heuristic Paradigm is the Best Choice for Social Work
}

\author{
by Jessica Heineman-Pieper, Katherine Tyson, \& Martha Heineman Pieper
}

\begin{abstract}
Social work today faces a crucial watershed: Will the field continue to promulgate unsound and detrimental beliefs about social work research and knowledge, or will the field fully embrace the heuristic paradigm and thereby realize its true potential as a first-rate science committed to humanistic ideals? Proponents of unsound and detrimental beliefs have obscured the choice for social workers by systematically and thoroughly misrepresenting the heuristic paradigm, making unwarranted and misleading claims for the paradigms to which it is opposed (logical empiricism and relativism), and confusing the issues at stake for the field. Accordingly, this article helps social workers recognize the tenets and implications of each of the three paradigms for research that social work has available to it-the heuristic paradigm, logical empiricism, and relativism-so that social workers can make a truly informed choice about the best approach to knowledge in their field.
\end{abstract}

\section{Introduction}

SOCIAL WORKERS TODAY face an unprecedented opportunity to place social work on unshakable scientific foundations that are also consistent with social work's long-standing humanistic values. Social workers can realize this opportunity only by definitively turning away from the unsound and detrimental set of beliefs derived from logical positivism (or logical empiricism, see below) and embracing the beliefs currently espoused in the philosophy of science and the "hard" sciences, and imported into social work by Martha Heineman Pieper (1981, 1989; Tyson, 1995) as the heuristic paradigm. Already, many social workers have chosen the heuristic paradigm for developing and evaluating social work research and knowledge: The heuristic paradigm is now taught in many masters and doctoral social work programs; research based on the heuristic paradigm has been published in several social work publications (D'Haene, 1995; Murdach, 1995; Heineman Pieper \& Pieper, 1992; Tyson, 1999, 2000; Tyson \& Carroll, 2001); there is increasing acceptance of methodological pluralism or "many ways of knowing"
(Davidson, 1988; Dean \& Fenby, 1989; Goldstein, 2000; Hartman, 1990; Laird, 1993; Saleebey, 1994; Weick, 1991; Witkin, 1995); and, in general, uncritical acceptance of the flawed logical empiricist paradigm has been replaced with a lively debate over which foundations we will choose for our field.

The heuristic paradigm is a metatheory of research that starts from the realization (already well known in up-todate philosophy of science and the hard sciences) that there are no privileged realities or ways of knowing, and therefore that there is no way to include all relevant information in data gathering and analysis. Thus, all ways of knowing (including all research methods) lose and distort some information in the process of gathering and analyzing data (that is, all acts of knowing rely on strategies, or heuristics). Following Wimsatt (1986) and Simon (1966), we define heuristics broadly as ways of perceiving, knowing, and solving problems (Bolland \& Atherton, this issue), give the definition of a heuristic as if it were the definition of the heuristic paradigm, but this conflates a concept with a research paradigm). Each way of knowing (each heuristic) tends to distort and lose information in systematic

Families in Society: The Journal of Contemporary Human Services

Copyright 2002 Families International, Inc. 
ways (have systematic biases; Wimsatt, 1981, 1986). Unlike prejudice, which refers to unjust and destructive attitudes towards others, bias, as used here, refers to the inevitable limitations on any one person's-or group's - perspective that accompany any act of knowing. Because all ways of knowing have systematic biases, it is better to recognize and manage these biases (as the heuristic paradigm teaches researchers to do) than to overlook or deny them (as the logical empiricist paradigm teaches researchers to do). In fact, as we will see, when logical empiricists overlook or deny the biases of their preferred ways of knowing and correspondingly overplay the biases in and devalue or reject other ways of knowing, bias is amplified well beyond the systematic but manageable levels of individual heuristics and becomes systemic (system-wide). Under logical empiricism, bias proliferates to the level of creating severe, unrecognized, and harmful distortions that pervade the entire knowledge base of the field. In contrast, the heuristic paradigm offers social workers powerful and effective conceptual tools-drawn from the philosophy of science and the hard sciences-that enable researchers to apply heuristics effectively and productively to reduce and manage bias, and to yield reliable, robust, and significant scientific knowledge (Callebaut, 1993; Heineman Pieper, 1981, 1989; Margenau, 1966; Sperry, 1983; Tyson, 1995; Wimsatt, 1981, 1986, 1987).

When Heineman Pieper first introduced the heuristic paradigm into social work 20 years ago, opponents categorically rejected the entire heuristic paradigm, including all of its component ideas (Bloom, 1990; Epstein, 1993; Geismar, 1982; Hudson, 1982; Schuerman, 1982). Later, some tried to overpower the heuristic paradigm through a show of superior force (misusing their numbers and status, e.g., Grinnell, Austin, Blyth, Briar, et al., 1994). (For an incisive analysis that illuminates why this may have happened, see Collins, 1990, p. 219, and Hartman, 1995.) Proponents of logical empiricism continue to constrain academic freedom (as documented by Cloward, 1998), devalue research contributions that do not match their unwarranted, methodologically-based criteria for scientific knowledge (Grinnell, 1997; Rubin \& Babbie, 2001; Task Force on Social Work Research, 1991; Williams, Unrau, \& Grinnell, 1998), create divisions between practitioners and researchers and between scientists and advocates (Gibbs, 1983; Reid, 1994a; Rubin \& Babbie, 2001; Thyer \& Myers, 1998), promote or exclude approaches to practice based solely on whether or not they are supported by a flawed and pervasively distorting (logical empiricist) approach to research (Myers \& Thyer, 1997; Reid, 1994a, 1994b; Thyer, 1991), and completely misrepresent the heuristic paradigm and the issues at stake for the field (Anastas \& MacDonald, 1994; Anastas, 1999; Bolland \& Atherton, this issue; Thyer, 1993; Williams, Unrau, \& Grinnell, 1998). These problems are exacerbated by logical empiricist textbooks that first thoroughly misrepresent the ideas and issues involved, and then do not even provide students with citations to the sources capable of rectifying these thoroughgoing misrepresentations (Grinnell, 1997; Royse, 1999; Rubin \& Babbie, 2001).

Interestingly, the ideas comprising the heuristic paradigm have by now achieved such wide appeal in social work that opposition to the heuristic paradigm has developed a surprising new form: (a) misrepresenting it as unnecessary, undesirable, or relativistic, while at the same time (b) incorporating entire portions of the heuristic paradigm, and then (c) combining the ideas appropriated from the heuristic paradigm with contradictory ideas drawn from the flawed logical empiricist approach to research. Examples of this new type of opposition occur in the article by Bolland and Atherton (this issue) and in the work of Anastas and MacDonald (1994), and Anastas (1999). These authors first thoroughly and systematically misrepresent and dismiss the heuristic paradigm. Then, they recommend fallible realism as if it were in opposition to the heuristic paradigm, when in fact fallible realism was originally imported into social work by Heineman Pieper $(1981,1987,1989)$ as part of the heuristic paradigm, and two papers elucidating this perspective were reprinted as foundations for the heuristic paradigm in Tyson's (1995) textbook (one by Bhaskar [1989] who calls it "transcendental" or "critical" realism [1975, 1991], and the paper by Manicas \& Secord [1983] to which Anastas \& MacDonald [1994], Anastas [1999], and Bolland \& Atherton refer). After claiming the heuristic paradigm opposes a "straw man" and that the legacy of logical empiricism is "dead" in social work (Bolland \& Atherton, this issue), these authors proceed to recommend logical empiricist concepts in their proposed frameworks for social work research (for example, Popper's ideas for research design and theory-testing, see below).

The occasion for this essay is a response to Bolland and Atherton (this issue). However, because Bolland and Atherton's article completely misrepresents the heuristic paradigm, logical empiricism, and the implications for social work of the choice between them, we have decided not to bore readers with what would have to be an endless catalogue of errors and corrections. Rather, we will help readers to understand why the choice of research paradigm is critically important for all social workers, why the heuristic paradigm is the only choice that will enable 
social work to achieve its true scientific and humanistic potential, and how to recognize logical empiricist and relativist research concepts, especially now that some logical empiricists are cloaking their beliefs in ideas appropriated from the heuristic paradigm.

\section{What is a Paradigm, and Why Should We Care?}

Some of our readers may wonder what a research paradigm really is and why the choice of a research paradigm is so important for social workers. In this section, we will briefly clarify the nature of a research paradigm and why it matters. Often those debating social work's choice of research paradigms conflate a research method and a research paradigm (metatheory) (e.g., Anastas \& MacDonald, 1994; Anastas, 1999; Grinnell, 1997; Mullen, 1995; Padgett, 1988; Royse, 1999; Rubin \& Babbie, 2001; Thyer, 1993). Research methods are systematic ways of knowing, such as ethnographic methods, experimental designs, and single and multiple case studies. Methods are chosen as part of the research design process when a researcher makes several decisions, including how to formulate the problem, what kind(s) of data to collect, how it will be collected, how it will be analyzed, and how he or she will reason from the data to the conclusions.

In contrast to a research method, a research paradigm is a set of fundamental assumptions, beliefs, and values that determines the bases on which we decide what counts as genuine scientific knowledge. As we shall see, social work has three research paradigms available to it, and each one has radically different consequences for the actual and possible contents of social work's knowledge base and the values the field can express.

The term "paradigm" was famously applied in the history and philosophy of science by Thomas Kuhn. Our definition of a paradigm and our examples of paradigms (heuristic paradigm, logical empiricism, relativism) more than meet Kuhn's definitions of the term. Whereas Kuhn warrants using the term paradigm for matching a single component of the "disciplinary matrix," the heuristic paradigm (like the other examples) matches all of Kuhn's stated components because it is, in fact, a full-fledged disciplinary matrix (or paradigm in the largest and fullest sense). Although a match with one of Kuhn's criteria would sufficiently justify our use of the term, we will illustrate matches with all four of Kuhn's criteria: (a) "symbolic generalizations"; (b) "the metaphysical parts of paradigms," "models," or commitments to beliefs; (c) "values"; and (d) exemplars (1970, p. 182-184).

Kuhn says symbolic generalizations are statements that function as laws in the sense that they are principles and "definitions of some of the symbols" the research community deploys (1970, p. 183). The generalizations may be cast in a logical or numeric form, or in words. Scientists subscribing to the paradigm share a common commitment to these generalizations. An example of such generalizations in the heuristic paradigm is, "All research methods are heuristic choices (and therefore their value is purpose- and context-relative), rather than intrinsically privileged ways of knowing" (Heineman Pieper, 1981, 1989; Tyson, 1995).

Kuhn states that paradigms consist of metaphysical parts, models, or commitments to beliefs (1970, p. 182-184). Kuhn also recognizes a range of depths at which these models or commitments operate, but all function to "determine what will be accepted as an explanation" (p. 184). Research paradigms operate at the deepest level of all, by determining the very structure of acceptable explanation. The heuristic paradigm, social work's logical empiricist paradigm, and relativism are all paradigms according to Kuhn's criterion. As will be shown below, they make (opposing) commitments to what can be explained or known and how it is possible to explain or know it.

Kuhn also defines a paradigm as comprised of shared values. He specifies that, "though they [values] function at all times," these values are especially critical "when the members of a particular community must identify crisis or, later, choose between incompatible ways of practicing their discipline," that these values are used in "judging whole theories," and that the values in paradigms determine decisions such as whether "science should (or need 
not) be socially useful" (Kuhn, 1970, pp. 184-185). As will become even more obvious when we outline their contrasting values, the heuristic paradigm, logical empiricism, and relativism are incompatible paradigms in exactly this sense.

Kuhn's final type of paradigm component is "exemplars," or "shared examples" (p. 186-191). Kuhn remarks that common, worked-out examples function "as a tool, informing the student what similarities to look for, signaling the gestalt in which the situation is to be seen," and teaching the student how to view "the situations that confront him as a scientist in the same gestalt as other members of his specialists' group" ( $\mathrm{p}$. 189). The importance of exemplars to both the heuristic paradigm and the logical empiricist paradigm is evident in the fact that, in their research textbooks, proponents of both paradigms devote considerable space to worked-out examples of how to apply the general research principles to specific research questions (Anastas, 1999; Grinnell, 1997; Rubin \& Babbie, 2001; Tyson, 1995).

Kuhn identifies two characteristics of paradigms that are especially relevant here. First, alternative paradigms are fundamentally contradictory and incompatible ("incommensurable"), even as they may incorporate the same lower level data, concepts, or theories. We will see how the heuristic paradigm, logical empiricism, and relativism are fundamentally incompatible frameworks for social work research, even though both the heuristic paradigm and logical empiricism incorporate experimental methods. Second, the diverse, defining components of paradigms (or "constituents of the disciplinary matrix") "form a whole and function together" (p. 182). This is why it is incoherent to "pick and choose" among the ideas of the heuristic paradigm and why attempts at "compromises" or "solutions" to the debates over social work's research foundations (e.g., Anastas, 1999; Anastas \& MacDonald, 1994; Bisman \& Hardcastle, 1999; Bolland \& Atherton, this issue; Peile, 1988) are both unnecessary and detrimental: they create fundamental inconsistencies in social work's approach to science and prevent social work research from replacing unsound logical empiricist ideas with the solid, coherent framework offered by the heuristic paradigm.
A research paradigm (metatheory) is fundamentally distinct not just from a research method but also from a theory. Bolland and Atherton conflate metatheories and theories when they assert that the heuristic paradigm, in welcoming diverse theories and ways of evaluating them (diverse ontologies and epistemologies), "has no distinctive disciplinary matrix composed of ordered elements" (p. 11) at the metatheory level. We have already shown this assertion to be false. Theories are a species of scientific knowledge, whereas metatheories set the conditions for scientific knowledge. Metatheories influence the form, construction, and evaluation of theories.

In order to fully understand research paradigms, it is important to understand the distinction between the process of science and the philosophy of science. Bolland and Atherton claim that a focus on the philosophy of science (a scientist's paradigm) is irrelevant to the process of science (pp. $11 \& 12$ ). They dismiss objections to Popper as "philosophical" and then misrepresent Popper's views as simply "the idea that knowledge changes because it is subject to challenge and review by other scientists" (p. 12). In fact, (with the sole exception of relativism, see below) all approaches to research-including the heuristic paradigm-recognize that challenge and review by other scientists is at the heart of generating scientific knowledge. As we will see, Bolland and Atherton, by invoking Popper, impose very specific and harmful beliefs about and prescriptions for social work research. Furthermore, it very much matters not just what scientists do (the process of science), but also what they think and intend to do (their philosophy of science). We will show how a scientist's fundamental assumptions and beliefs (philosophy of science) significantly affect the quality of her or his science.

Historians and philosophers of science demonstrated 50 years ago that one of the flaws of logical empiricism is that its beliefs about scientific knowledge do not match the process of what scientists actually do (Hanson, 1958; Hull, 1988; Kuhn, 1970). In the field of social work, the wide chasm between what logical empiricist researchers were actually doing (their process, which like all research has inevitably relied on heuristics) and what these re- 
searchers claimed they were doing (their philosophy, which held that some ways of knowing were intrinsically less biased), caused bias to proliferate unregulated, values to operate invisibly (and often undesirably), and scientific quality to be fundamentally compromised (Heineman Pieper, 1981, 1989; Tyson, 1995).

We can now see why social work's choice of a research paradigm is of paramount importance for the future of our field and our society. Because it determines the bases on which we evaluate knowledge claims, the paradigm shapes the actual and possible contents of social work knowledge, including the possible value positions that can be expressed within that knowledge base. The paradigm regulates the discoveries social workers can make and endorse about issues important to the welfare of society. By determining what we can know, the paradigm centrally impacts the sorts of practices and policies we design, and what kinds of values we build into our personal, professional, and societal relationships. In the next section, we present the three paradigms available to social workers today and show the implications of each for social work knowledge and values.

\section{Paradigms in Social Work Research Today}

\section{Logical Empiricism}

First introduced into social work in the 1950s (Social Work Research Group, 1955), the logical empiricist paradigm of social work research quickly took over the field (Tyson, 1995). Starting in 1981, Heineman Pieper exposed the hegemonic operation of this paradigm in social work, detailed its roots in the failed logical empiricist philosophy of science, and demonstrated its significant adverse effects on social work research and knowledge. Although the logical empiricist paradigm has since lost ground, it continues to have a significant and detrimental impact on our field (documented in Heineman Pieper, 1994; Saleebey, 1989; Tyson, 1992; Weick, 1991; Witkin, 1993, 1998), and social workers are better prepared to recognize and excise it when they understand its core tenets.

Although positivist ideas have existed since antiquity, social workers imported the very restrictive brand of positivism that was developed in Vienna between the two World Wars and was called logical positivism (subsequently, logical empiricism). Logical positivism was the product of a group of philosophers of science, most notably Carnap, Neurath, Schlick, and Waissman. As described by a founding logical positivist, Carnap, these philosophers
... assumed that there was a certain rock bottom of knowledge, the knowledge of the immediately given, which was indubitable. Every other kind of knowledge was supposed to be firmly supported by this basis and therefore likewise decidable with certainty. (Carnap, 1991, p. 57)

To achieve their aim of certain scientific knowledge, the logical positivists advanced two primary commitments: (a) to use methodological and other structural criteria to differentiate scientifically meaningful propositions from those they deemed scientifically "meaningless," and (b) to excise values, subjectivity, and ontological premises (fundamental assumptions about reality) from scientific theories and the process of theory testing (identified in Hanfling, 1981; Scriven, 1969).

Initially, the logical positivists required that, in order to be scientifically meaningful, propositions had to be "verifiable" or "testable" (Carnap, 1936). However, their position was almost immediately debunked as untenable by other philosophers of science, and so they retreated to a less stringent criterion that, in order to be scientific, propositions should be testable in principle, that is that one could envision a way of testing one's proposition even if one could not carry it out (Hempel, 1965). They called this variant "logical empiricism." Within a few decades, logical positivism and logical empiricism had both been discarded as irredeemably unsound by the hard sciences and by leading philosophers of science (Einstein, 1959; Hanson, 1958; Kuhn, 1970; Margenau, 1966; Quine, 1948; Scriven, 1969; Suppe, 1977).

Despite the sound debunking in philosophy and the hard sciences, some of the ideas espoused by the Vienna Circle rose from the dead to be reborn in the social and behavioral sciences and in social work during the 1950s. In this reincarnation, logical empiricist ideas had three primary features (identified in Brown, 1977; Heineman Pieper, 1981, 1989; Scriven, 1969; Tyson, 1995): (a) theory-testing could and should eliminate induction (reasoning from the specific to the general) and rely solely on deduction (reasoning from the general to the specific) (e.g., Wallace, 1971), (b) certain methodological and other structural criteria (such as whether or not the method used "operationalized" data and/or experimental design) offered a privileged way to evaluate knowledge claims, and (c) values (including, for instance, advocacy for social justice) could and should be eliminated from science. For scientific contexts, the imported ideas functionally erased the distinction the Vienna Circle philosophers made between logical positivism and logical empiricism. Accordingly, for 
the purposes of social work research, the terms logical empiricism and logical positivism are interchangeable.

Each of the three assumptions will be discussed in turn. First, whereas logical empiricists in social work attempt to structure the research process so that there is a hierarchy of methods in which some (often deemed exploratory or qualitative, e.g. Grinnell, 1997; Rubin \& Babbie, 2001; Williams, Unrau, \& Grinnell, 1998) are acknowledged to rely heavily on induction, but others are thought to avoid induction, contemporary philosophers and scientists in the hard sciences recognize that scientific knowledge invariably entails countless instances of induction, and that any empirical investigation relies upon induction in myriad ways at every step of the research process (e.g., induction is required whenever we define a concept, choose a theory to test, or decide whether or not a hypothesis has been disproven, Heineman Pieper, 1981; Salmon, 1971, 1989). Accordingly, social work researchers cannot eliminate induction; they can only blind themselves to the inductive processes they are using. For example, logical empiricist social work researchers promote such blindness when they falsely assert that "empirical methods" can operate independently of theories and can provide neutral, "theory-free" evidence for or against them (Grinnell, 1997; Reid, 1994a, 1994b; Rubin \& Babbie, 2001; Myers \& Thyer, 1997; Thyer, 1991, 2001).

Second, "structural" considerations such as types of data and methodologies are an extremely unreliable basis for deciding the quality of research products. All ways of gathering data, and all methodologies, entail systematic biases. For instance, as Danziger (1985) pointed out, designs that use large samples maximize anonymity and similarity according to predetermined criteria, and minimize the subjects' differences, by comparison with designs that preserve the unique, diverse meanings of a small sample of subjects. Researchers using the heuristic paradigm recognize that the value of particular methods can only be ascertained in relation to, among other considerations, the question the scientist wants to answer and the theory the scientist is using to address it. Although some logical empiricist social workers claim to recognize this fact, in reality they belie their claims by continuing to uphold hierarchies of types of data and methods (Grinnell, 1997; Rubin \& Babbie, 2001; Thyer \& Myers, 1998; Williams, Unrau, \& Grinnell, 1998). One destructive consequence of logical empiricist methodological prescriptions is that social work research lost its relevance to practitioner concerns and real world problems (McNicoll, 1999; Saleebey, 1979; Salomon, 1967; Vigilante, 1974; Wainstock, 1994) because social work researchers unrecognizably transformed their research questions on the procrustean bed of logical empiricists' preferred methodologies (such as a stringent, quantitatively-based operationism). Even more destructive, because such methodological prescriptions are unwarranted, they are misleading standards for developing and evaluating scientific knowledge and fundamentally compromise the quality and value of social work's scientific knowledge base.

Third, it is impossible to eliminate values and subjectivity from science (Avis, 1994; Bhaskar, 1989; Lather, 1986a, 1986b; Sperry, 1983), and, as Scriven (1969) pointed out, even the effort to do so reflects a value choice. For social workers, it is both an impossible and a completely undesirable aim. As a result of logical empiricist prohibitions against adopting an explicit value position, social work research and knowledge was forced to express and reinforce an unreflective, unchosen status quo (Heineman Pieper, 1981, 1989, 1994; Tyson, 1995).

Not only does logical empiricism's general stance against explicit value positions (such as advocacy) force social work research to abet an unreflective, unchosen status quo, but also the specification of broadly preferred data types and methods that researchers preferentially apply irrespective of their local research contexts itself embodies specific values. Yet, because alternative approaches are disallowed by logical empiricists, social workers educated in the logical empiricist tradition are unaware both of what they are endorsing and of what they could be endorsing (what they are missing). 
Some authors (Bolland \& Atherton, this issue) try to argue that logical empiricism is "dead" in social work. Ironically, these same authors (like many others, such as Grinnell, 1997; Reid, 1994a, 1994b; Rubin \& Babbie, 2001; Thyer, 1991) recommend logical empiricist ideas to social workers in the here-and-now. For example, Bolland and Atherton (this issue) attempt to elevate Sir Karl Popper's deductive method of theory testing and falsification as a viable alternative to logical empiricist ideas and as a shining example for the future of social work research. Although Popper, who met with the Vienna Circle logical positivists, was aware of many of the logical positivists' errors and did not call himself a logical positivist, he sought to fulfill their unattainable and misguided aim of eliminating induction from theory-testing so as to arrive at certain scientific knowledge. In fact, as many scholars have demonstrated, Popper's reformulations rest on the same basic logical empiricist foundations already outlined and come apart on the same shoals (Mitroff, 1973; Nickles, 1987; Suppe, 1977, esp. citing Putnam, p. 424ff; Tyson, 1995).

Popper's hypothetico-deductive method sets out strict criteria for how scientists should proceed in testing theories: creating a (harmful and artificial) categorical divide between theory testing and the process of discovery, deducing a prediction from a theory, eliminating retrospective designs, and privileging certain kinds of data (e.g. "raw" sense data) that are falsely believed to be more "basic" and "objective" (and thus acceptable for the "critical" tests). When Bolland and Atherton state that Popper's hypothetico-deductive method "openly starts from a theory" (p. 4), they falsely imply that Popper recognized that no ways of knowing are ever theory- or value-free. In fact, Popper's hypothetico-deductive method mentions theories only to replicate the logical empiricist divide between "theories," interpreted as logical structures, and "facts" or observations, which are presumed to be so theory- and value-neutral that scientists can tell if a theory is false if a finding from a single ("critical") experiment disconfirms it (Popper, 1959). Contemporary philosophers of science recognize that there are no neutral, "critical" tests, because there are no unmediated reports from nature (no experiment or finding can ever speak for itself). Instead, credibility results from a series of choices made by the researcher and the evaluations by her or his scientific community (Callebaut, 1993; Galison, 1987; Wimsatt, 1981, 1987).

Like Popper's hypothetico-deductive method, Popper's doctrine of falsification fails to effect his hoped-for separation from the logical empiricists. Popper turned to "falsification"- the requirement that research questions be formulated so that they could be "disconfirmed" by one finding - to try to avoid the problem of induction that had dashed the logical empiricists' hopes of constructing a superior, privileged methodology (Popper, 1959). Yet, as Wesley Salmon (1971) showed, induction is equally indispensable to the falsification as to the confirmation of theories, because no matter how many hypotheses we falsify, there will always be other possible alternatives that are consistent with our data, and any attempt to choose among these requires induction (Heineman [Pieper], 1981; Salmon, 1971; Tyson, 1995). Moreover, induction is indispensable even to the decision that a single theory is ever definitively "falsified," because induction undergirds the belief that the theory will continue to appear false at other times, places, and contexts.

Thus, rather than being an alternative to the logical empiricist perspective, Popper's hypothetico-deductive method and falsification are simply another expression of it. By advocating that social workers adhere to Popper's formulations, Bolland and Atherton's work proves that the heuristic paradigm is debunking not a straw man but current and pervasive-though false-beliefs.

The adoption of logical empiricism, including Popper's methods, in social work has constituted a giant leap backwards, both for the scientific rigor of social work's knowledge base and for the field's ability to accomplish its stated mission. Because logical empiricism's misleading and unwarranted restrictions prevent social work from accurately evaluating what does and does not constitute knowledge, the logical empiricist research paradigm undermines the capacity of social work's knowledge base ever to achieve its true scientific potential. Among other problems, logical empiricist social work researchers: (a) rejected as "unscientific" the original, path-breaking research contributions of its founders (such as Jane Addams, Sophonisba Breckinridge, Edith Abbott, and Mary Richmond) (see, for instance, Austin, 1978; Briar, 1979; Reid, 1994a; Schuerman, 1987); (b) set up structural impediments to social work's accomplishment of its mission of advocacy (as in Gibbs, 1983; Rubin \& Babbie, 2001); (c) devalued research methods that practitioners in the trenches could most readily use to generate knowledge relevant to improving services, creating a gulf between practitioners and researchers (as in Grinnell, 1997; Task Force on Social Work Research, 1991; Thyer, 1989); and (d) set up criteria that stifled the originality and scientific development of social workers that began from the moment of their education in logical empiricist social work research and extended through publication standards and criteria for promotion and tenure of faculty (documented 
in Cloward, 1998; Hartman, 1990; Heineman Pieper, 1989; McNicoll, 1999; Tyson, 1995; Weick, 1992)

\section{Relativism}

It is ironic that the heuristic paradigm is often confused with relativism (Anastas, 1999; Anastas \& MacDonald, 1994; Bloom, 1990; Bolland \& Atherton, this issue), because relativism is more akin to logical empiricism than it is to the heuristic paradigm: Relativism shares logical empiricism's fundamental aversion to reliance on the scientist's informed judgment, and also denies that a researcher adopting a (relativist/logical empiricist) paradigm inevitably is making theory and value commitments. In scientific contexts, relativism holds that there is no rational basis for deciding how accurate or inaccurate a theory or evidence is vis-à-vis the reality it seeks to describe (defined in NewtonSmith, 1984, p. 369-370; Tyson, 1995 , p. 514). Because rationality is deemed impotent to evaluate the quality of knowledge claims, relativists believe that what is "real" (or true) is ultimately determined by arbitrary or idiosyncratic personal preference or social influences like power.

Although few social workers say they are relativist, some unknowingly advance relativist ideas when they say that all values are so culturally dependent that we can-
Since informed judgment is the only sound basis for evaluating scientific knowledge, relativism, like logical empiricism, undermines the scientific quality and value of social work knowledge. discussion and to devalue the exercise of rational, informed judgment. Since informed judgment is the only sound basis for evaluating scientific knowledge, relativism, like logical empiricism, undermines the scientific quality and value of social work knowledge.

\section{The Heuristic Paradigm}

The heuristic paradigm is the only paradigm for social work research that is grounded in coherent conceptual and scientific foundations, and that is consistent with social work's humanistic values and ideals. Moreover, the heuristic paradigm provides social workers with an entire toolbox for understanding, designing, and evaluating scientific social work research. Here, we will provide a brief summary of a few of the main characteristics of the heuristic paradigm. For more indepth descriptions, we refer our readers to our previous works (Heineman Pieper 1981, 1982a, 1982b, 1986a, 1986b, 1987, 1988, 1989, 1994; Heineman Pieper \& Tyson, 1999; Tyson, 1992, 1994a, 1994b, 1994c, 1995 ) and to the sources, fully referenced in our writings, from which we have drawn.

As we indicated earlier, the heuristic paradigm starts from the realization that there are no privileged realities and no inherently superior modes of knowing. As a not legitimately advance humanistic values as an ideal for our field. Another manifestation of relativism is the belief that it is pointless or even harmful to develop formulated theories because theories are assumed to be nothing more than depositories of social contextual influences. This type of relativist believes that science is such a deeply irrational process that we are better off being skeptics about all theories. But as many have long recognized, this is in fact just another form of theory (Heineman Pieper, 1981; Scriven, 1969). Moreover, when it comes to the moment of actually formulating something to do with a client (or clients), social workers, like all scientists, inevitably choose a theory (Heineman Pieper, 1989; Tyson, 1995).

Relativism has a destructive impact for social work that has not been sufficiently recognized. The assumption that knowledge claims cannot be decided rationally leads relativists to deny the possibility of reflective and meaningful result, there is no way to include all relevant information in data gathering or analysis (no way to avoid induction). All research methodologies therefore lose and distort some information in the process of gathering and analyzing data (all research methodologies are examples of "heuristics," see below). In fact, each methodology and each family of methodologies tends to lose and distort information in systematic ways (Danziger, 1985; Wimsatt, 1981, 1986).

Heuristics are ways of perceiving, knowing, or solving problems. Because all heuristics (including the methodologies favored by the logical empiricists) inevitably lose and distort information, and because different heuristics lose different kinds of information and introduce different types of distortions (Wimsatt, 1986), all heuristics are inescapably purpose- and context-relative (even when the researchers who implement them are not aware of this fact 
and make false claims for the status of their methods and results). For example, in preserving more of some kinds of information, heuristics entirely jettison other kinds of information. When the reality of interest to a researcher does not generate information of the kind the heuristic preserves, that reality cannot be known using that heuristic.

These tenets have several vital implications. First, because all research includes systematic biases (relies on heuristics), these biases can only be managed when researchers actively identify and govern them (using the tools for bias recognition and management provided by the heuristic paradigm and its sources), not when researchers overlook or deny them (as logical empiricists do).

Second, the heuristic paradigm recognizes that bias is reduced and truth promoted not by logical empiricists' restrictiveness but rather by diversity and inclusiveness that welcome a full range of questions, methods, approaches, and value positions. Building on this realization, the heuristic paradigm enables social workers to ask whatever questions they find most interesting and to address them using whatever theories, approaches, systems, data, and contexts they find most relevant and useful. As a result, the heuristic paradigm provides complete availability to diversity in what can be studied and how it can be studied-without succumbing to relativism. In contrast, because logical empiricists restricted social work researchers to particular types of data and required that data be operationalized or reducible to basic sensory impressions, they profoundly circumscribed the kinds of realities that can be known in social work. Many issues of great import for social workers are included among the aspects of reality that cannot be effectively studied under logical empiricist restrictiveness, such as motives, injustice, empowerment, society, values, and meanings. Far from reflecting a lack of a fundamental commitment to what Kuhn called a disciplinary matrix (as Bolland \& Atherton assert), the heuristic paradigm's welcoming of diverse ontologies and ways of knowing is in itself a commitment that is completely in accord with and makes it possible for social work to accomplish its traditional mission.

Third, unlike logical empiricism, which constructs hierarchies of more and less preferred methods, the heuris- tic paradigm recognizes that decisions about research design should not be made at the paradigm level, as logical empiricism tries to do, but should be decided by the individual researcher held to the exacting standards of explaining and justifying his/her choice to the research community. The heuristic paradigm is the only paradigm for social work research that offers a conceptually sound and effective basis for evaluating the quality, meaning, and value of scientific research and knowledge. The heuristic paradigm follows the lead of the hard sciences in recognizing that informed judgment is the best and only ultimate standard we have for evaluating scientific research and knowledge, and it offers logically sound conceptual tools (as opposed to the unsound methodological prescriptions of logical empiricism) for honing informed judgment so that it can be a fully adequate basis. Logical empiricism and relativism are both at odds with established wisdom in the hard sciences and up-to-date philosophy of science, because both of these paradigms devalue informed judgment by denying its centrality to the meaningful evaluation of knowledge claims: Logical empiricism denigrates informed judgment as untrustworthy, and relativism denigrates it as impotent. When logical empiricists privilege methodological and other structural markers for evaluating research, they actually undermine the effective exercise of informed judgment.

Fourth, the heuristic paradigm recognizes that one of the scientist's most challenging tasks is to truly understand her or his assumptions, values, options, and choices, including their implications, at every step of the research process, and to apply this understanding to effective research design and evaluation. Accordingly, among the most important contributions of the heuristic paradigm are the tools it offers, imported from postpositivist philosophers of science, for identifying the heuristics entailed in all research design decisions, ranging from choices of research questions (including diverse types of systems and causes), to choices of theories, values, and methods of data collection and data analysis. These tools help researchers become thoroughly reflective and truly expert at designing their research and at recognizing and evaluating their own and others' research choices. For instance, 
Tyson (1995) elaborated many standards for theory evaluation using the heuristic paradigm, including the scope of the theory; the theory's ability to explain phenomena we need to explain, including anomalies not explained by other theories; the logical consistency among assumptions, concepts and principles; and the entailed values, including the theory's relevance to the field and its impact on social inequalities and advocacy. To give a different kind of example, William Wimsatt (1981, 1986, 1987), a philosopher of science whose work is central to the heuristic paradigm, teaches researchers how to reduce bias and increase robustness by examining the same reality using heuristics that carry relevantly different biases. The heuristic paradigm lets social workers leverage what they might experience as an unfortunate (though inescapable) reality (i.e., the true impossibility of certain or privileged knowledge) into a powerful asset (i.e., robust, significant knowledge built on heuristics that have been wisely and effectively applied to the research context).

The choice of research paradigm for social work has significant implications for the values possibly and actually expressed by the field. We have already seen how the logical empiricist research paradigm forces social work research and knowledge to advance the status quo and prevents social work from developing research and knowledge drawn from alternative value positions. Unlike logical empiricism, which imposes a single, unreflective value position on the field, the heuristic paradigm recognizes that both truth and goodness rely on the availability to diversity combined with the freedom to make informed, considered choices, plus the commitment to share the details of the research process with the rest of the field to allow others to make their own informed judgments about the meaning and value of the research results. Under the heuristic paradigm, researchers reflectively and explicitly identify and choose the values they express in their research.

Many opponents of the heuristic paradigm seek to dismiss it by thoroughly and systematically misrepresenting it. One of the most persistent of these misrepresentations conflates the heuristic paradigm with naturalistic methods and falsely asserts that the heuristic paradigm opposes experimental or interventionist methods (Anastas, 1999; Anastas \& MacDonald, 1994; Anastas \& Congress, 1999; Mullen, 1995; Padgett, 1998). In fact, the heuristic paradigm embraces the full complement of types of rigorous data and methods as potentially useful tools, and recognizes that research design decisions should not be prioritized by a research paradigm, but rather should be made by the individual researcher with a particular research question and context in mind. As Heineman Pieper (1989) explained, "the rules of the experimental method are examples of heuristics. Understood as heuristics, they are potentially useful research tools" (Heineman Pieper, 1989 , p. 11). Thus, the heuristic paradigm is thoroughly inclusive with regard to types of rigorous methods and data, even as it unconditionally rejects the false claims logical empiricists make for those methods, and even as it insists on an accurate and reflective understanding (metatheory) of the research process.

\section{Three Paradigms for Social Work Research: The Choice for Social Workers}

Social work can opt for one of three paradigms of research. These paradigms are all fundamentally opposed to and incompatible with each other, because each decides research quality and knowledge claims on fundamentally different and opposed bases, and each expresses and encourages completely different values. In terms of the bases for evaluating knowledge claims, relativism claims that there is no rational basis on which to evaluate knowledge claims, and that therefore such evaluation is merely a matter of arbitrary personal and social preference driven by power and interest. The logical empiricist research paradigm erroneously assumes that particular types of methods and data are intrinsically more immune to bias and intrinsically more trustworthy than other defensible types of methods and data, and prescribes the preferred methods and data for all contexts. Other methods and data are only used when the preferred types simply aren't 
feasible, and then the knowledge they yield is devalued (for example, as merely "exploratory," requiring use of the preferred methods to provide "confirmation").

The heuristic paradigm claims that both logical empiricism and relativism are fundamentally misguided and destructive. While structural (including methodological) criteria are incapable of providing an accurate guide to the quality of research products and other knowledge claims, the evaluation of knowledge claims can, in fact, be made rationally, intelligently, and scientifically - by relying on informed human judgment. The heuristic paradigm further helps social workers to hone their informed judgment by presenting the best and most up-to-date conceptual tools available in contemporary philosophy of science and in the hard sciences. $\mathrm{Al}$ though some logical empiricist authors assert that they value researchers' informed judgment and appreciate its importance in, for example, selecting methods to fit the research problem, in fact they belie their assertions by simultaneously endeavoring to shackle that judgment to fundamentally logical empiricist assumptions about the research process, including the hierarchies of broadly preferred methods. By contrast, the heuristic paradigm genuinely recognizes and appreciates the significance of informed judgment to the design and evaluation of scientific research and provides social workers with the tools they need to use their judgment fully and effectively. Armed with the heuristic paradigm's conceptual tools, readers can make accurate and informed decisions about the quality and trustworthiness of their own and others' research products.

The three paradigms of social work research also express opposing values. Relativism ultimately expresses solipsism (Descartes, 1993/1637) — the viewpoint that legitimate, shared knowledge is impossible. In denying a rational basis for evaluating differing knowledge claims, relativism subjugates truth and goodness to arbitrary personal preference and social influences like power, thereby also ex- pressing the value of might makes right (or true). Because relativism explicitly states that all values are equal and there is no basis for preferring any one theory, it completely undermines social workers' rational basis for making judgments about inequality, and hence our efforts to bring about a more just society. In practice, however, social workers are not relativists-they recognize that some cultural values, such as racism, perpetuate social injustices. Our science needs to be nonrelativist in order to be able to identify those injustices and remedy their effects.

By preventing the explicit choice of values in scientific research, and forcing a divorce of science and advocacy, logical empiricism imposes a totalitarian set of values that supports the status quo. In addition, by limiting scientific inquiry to a restricted set of privileged methods, logical empiricism prevents science from transcending the particular biases of those methods, which when applied to the context of human relationships and development, obstructs the study of realities that are in fact vital for social workers to understand. In contrast, only under the heuristic paradigm can researchers make a reflective choicetake value positions explicitly, have free choice about research designs, and be capable of thoughtful discussion and evaluation of research, theories and values.

\section{Conclusion}

We have shown how social workers today face the crucial choice of which foundations they will choose for the field: relativism, logical empiricism, or the heuristic paradigm. We have shown how logical empiricism and relativism undercut-and how the heuristic paradigm enhances - social workers' efforts to generate relevant, significant, and accurate social work knowledge and to fulfill their humanistic and professional ideals. Because proponents of logical empiricist beliefs have obscured the choice for social workers by misrepresenting all aspects of the debates over social work's research foundations, this article clarifies the 
tenets of-and the implications for social work of adopting - each of the three paradigms of social work research.

By welcoming the full complement of rigorous research methods and types of data, by encouraging social workers to address whatever questions they find most important in whatever ways they find most useful, and by giving social workers the needed tools to accurately understand their own and others' research choices, the heuristic paradigm heals the unnecessary divisions in social work, such as between researchers and practitioners, between proponents of different research methods, and between proponents of different theories. Some logical empiricists repeatedly misrepresent the heuristic paradigm as opposing experimental methods, but we have shown that in fact it is only logical empiricism that favors and disfavors research methods at the paradigm level, and that the heuristic paradigm warmly welcomes all rigorous research methods and types of data-and fully empowers researchers to decide the best way to address their own research questions and contexts. The heuristic paradigm guarantees research quality not by misguidedly instituting structural rules and requirements, but instead by relying on informed judgment (the same standard as in the hard sciences) — and then helping social workers to cultivate and hone their informed judgment about research design and evaluation. Because it insists on an accurate and reflective understanding of the research process, the heuristic paradigm opposes only the misleading and harmful claims about research that are the defining characteristics of logical empiricism and relativism - not any of the research methods or particular theories that might have been researched under those paradigms. All of these research methods and theories can (far more effectively) be applied from within the heuristic paradigm.

In sum, we have shown how only the heuristic paradigm provides social workers with a thoroughly $\mathrm{co}^{-}$ herent, accurate, and unifying understanding of the research process and also the tools to use that understanding to generate robust, meaningful, and effective social work knowledge capable of sensitively informing social work practice and sustaining all of social work's treasured ideals. Dispelling the repeated and thoroughgoing misrepresentations advanced by proponents of logical empiricist and relativist social work research paradigms, this paper helps social workers to make a truly informed and reflective choice. By fully embracing and choosing the heuristic paradigm, social work can realize its true potential as a first-rate science committed to humanistic ideals.

\section{References}

Anastas, J. (1999). Research design for social work and the human services. New York: Columbia University Press.

Anastas, J. \& Congress, E. (1999). Philosophical issues in doctoral education in social work: A survey of doctoral program directors. Journal of Social Work Education 35(1), 143-154.

Anastas, J. \& MacDonald, M. L. (1994). Research design for social work and the human services. New York: Lexington Books.

Austin, D. (1978). Research and social work: Educational paradoxes and possibilities. Journal of Social Service Research, 2, 159-176.

Avis, J. M. (1994). Advocates versus researchers-A false dichotomy? A feminist, social constructionist response to Jacobson. Family Process, 33, 87-91.

Bhaskar, R. (1975). A realist theory of science. Leeds, England: Leeds Books.

Bhaskar, R. (1989). Reclaiming reality: A critical introduction to contemporary philosophy. London: Verso.

Bhaskar, R. (1991). Philosophy and the idea of freedom. Cambridge, England: Basil Blackwell.

Bisman, C. \& Hardcastle, D. (1999). A model for using research methodologies in practice. Journal of Teaching in Social Work, 19, 47-63.

Bloom, M. (1990). On the epistemology of social work practice knowledge. In L. Videka-Sherman \& W. J. Reid (Eds.). Advances in clinical social work research. Silver Spring, MD: National Association of Social Workers Press.

Bolland, K. \& Atherton, C. (2001). Heuristics versus logical positivism: Solving the wrong problem. Families in Society, 82, 591-603.

Briar, S. (1979). Incorporating research into education for clinical practice in social work: Toward a clinical science in social work. In A. Rubin \& A. Rosenblatt (Eds.). Sourcebook of research utilization. New York: Council on Social Work Education.

Brown, H. (1977). Perception, theory and commitment: The new philosophy of science. Chicago: University of Chicago Press.

Callebaut, W. (1993). Taking the naturalistic turn, or how real philosophy of science is done. Chicago: University of Chicago Press.

Carnap, R. (1936). Testability and meaning. Philosophy of Science 3: 420-471.

Carnap, R. (1991). Intellectual autobiography. In P. A. Schlipp (Ed.), The philosophy of Rudolf Carnap. Library of living philosophers: Vol. 11. LaSalle, IL: Open Court Press.

Collins, P. H. (1990). Black feminist thought: Knowledge, consciousness, and the politics of empowerment. New York, Routledge.

Danziger, K. (1985). The methodological imperative in psychology. Philosophy of the Social Sciences 15, 1-13.

Davidson, M. (1988). Advocacy research: Social context of social research. In C. Jacobs \& D. Bowles (Eds.) Ethnicity and race: Critical concepts in social work (pp. 114-130). Silver Spring, MD: National Association of Social Workers.

Dean, R., \& Fenby, B. (1989). Exploring epistemologies: Social work action as a reflection of philosophical assumptions. Journal of Social Work Education, 25, 46-54.

Descartes, R. (1993). Discourse on method and meditations on first philosophy, $3^{\text {rd }}$ ed. Donald A. Cress (Trans.). Indianapolis, IN: Hackett. (Original work published 1637.)

D'Haene, Maria. (1995). An evaluation of feminist-based adolescent group therapy. Smith College Studies in Social Work, 65, 153-166.

Einstein, A. (1959<1934>). Letter to Sir Karl Popper. In K. Popper (Ed.), The logic of scientific discovery. New York: Basic Books. 
Epstein, W. (1993). Randomized controlled trials in the human services. Social Work Research and Abstracts, 29, 3-10.

Galison, P. (1987). How experiments end. Chicago: University of Chicago Press.

Geismar, L. L. (1982). Comments on "The obsolete scientific imperative in social work research." Social Service Review, 56, 311-312.

Gibbs, L. (1983). Evaluation research: Scientist or advocate? Journal of Social Service Research, 7, 81-92.

Goldstein, H. (2000). Dignity. Families in Society, 81, 115-117.

Grinnell, R. (1997). Social Work Research \& Evaluation: Quantitative and Qualitative Approaches (5th ed.). Itasca, IL: Peacock.

Grinnell, R. M., Austin, C. D., Blythe, B. J., Briar, S., et al. (1994). Social work researchers' quest for respectability. Social Work, 39, 469-470.

Hanfling, O. (1981). Logical positivism. New York: Columbia University Press.

Hanson, N. R. (1958). Patterns of discovery: An inquiry into the conceptual foundations of science. Cambridge, England: Cambridge University Press.

Hartman, A. (1990). Many ways of knowing. Social Work, 35, 3-4.

Hartman, A. (1995). Introduction. In K. Tyson (Ed.). New foundations for scientific social and behavioral research: The heuristic paradigm. Needham Heights, MA: Allyn \& Bacon.

Heineman (Pieper), M. (1981). The obsolete scientific imperative in social work research. Social Service Review, 55, 371-396.

Heineman (Pieper), M. (1982a). Author's reply. Social Service Review, $56,146-148$.

Heineman (Pieper), M. (1982b). Author's reply. Social Service Review, 56, 312. (See also Pieper, M. Heineman.)

Hempel, C. G. (1965). Aspects of scientific explanation and other essays in the philosophy of science. New York: The Free Press.

Hudson, W. (1982). Scientific imperatives in social work research and practice. Social Service Review, 56, 246-258.

Hull, D. (1988). Science as a process: An evolutionary account of the social and conceptual development of science. Chicago: University of Chicago Press.

Kuhn, T. S. (1970). The structure of scientific revolutions (2nd ed.). Chicago: University of Chicago Press.

Laird, J. E. (Ed.). (1993). Revisioning social work education: A social constructionist approach. Binghamton, NY: Haworth Press.

Lather, P. (1986a). Issues of validity in openly ideological research: Between a rock and a soft place. Interchange, 17, 63-84.

Lather, P. (1986b). Research as praxis. Harvard Educational Review, $56,257-277$.

Manicas, P. T., \& Secord, P. F. (1983). Implications for psychology of the new philosophy of science. American Psychologist, 38, 399-413.

Margenau, H. (1966). The philosophical legacy of quantum theory. In R. Colodny (Ed.), Mind and cosmos: Essays in contemporary science and philosophy (pp. 330-356). Pittsburgh, PA: University of Pittsburgh Press.

McNicoll, P. (1999). Issues in teaching participatory action research. Journal of Social Work Education, 35, 51-62.

Mitroff, I. (1973). Systems, inquiry, and the meanings of falsification. Philosophy of Science, 40, 255-276.

Mullen, E. J. (1995). Pursuing knowledge through qualitative research. Social Work Research, 19, 29-32.

Murdach, A. (1995). Clinical practice and heuristic reasoning. Social Work, 40, 752-758.

Myers, L. \& Thyer, B. (1997). Should social work clients have the right to effective treatment? Social Work 42: 288-298.
Newton-Smith, W. (1985). Relativism. In W. F. Bynum, E. J. Browne, and R. Porter (Eds.). Dictionary of the History of Science. Princeton, NJ: Princeton University Press.

Nickles, T. (1987). 'Twixt method and madness. In N. J. Nersessian (Ed.), The process of science . Dordrecht, Netherlands: Kluwer Academic Publishers.

Padgett, D. (1998). Does the glove really fit? Qualitative research and clinical social work practice. Social Work, 43, 373-381.

Peile, C. (1988). Research paradigms in social work: From stalemate to creative synthesis. Social Service Review, 62, 1-19.

Pieper, M. Heineman. (1986a). The author replies. Social Work Research and Abstracts, 22, 2.

Pieper, M. Heineman. (1986b). Some common misunderstandings of the heuristic approach. Social Work Research and Abstracts, 22(2) 22.

Pieper, M. Heineman. (1987). Comments on 'Scientific imperatives in social work research: Pluralism is not skepticism.' Social Service Review, 61, 368-370.

Pieper, M. Heineman. (1988). Comments on 'Research paradigms in social work: From stalemate to creative synthesis.' Social Service Review, 62, 535-536.

Pieper, M. Heineman. (1989). The heuristic paradigm: A unifying and comprehensive approach to social work research. Smith College Studies in Social Work, 60, 8-34.

Pieper, M. Heineman. (1994). Science, not scientism: The robustness of naturalistic clinical research. In E. Sherman and W. J. Reid (Eds.), Qualitative research in social work. New York: Columbia University Press.

Pieper, M. Heineman. (1995). Preface. In K. Tyson (Ed.), New foundations for scientific social and behavioral research: The heuristic paradigm. Needham Heights, MA: Allyn \& Bacon.

Pieper, M. Heineman, \& Pieper, W. J. (1992). It's not tough, it's tender love. Child Welfare, 71, 369-377.

Pieper, M. Heineman, \& Tyson, K. (1999). Response to Padgett's 'Does the glove really fit?' Social Work, 44, 278-279. (See also Heineman (Pieper), M.)

Popper, K. R. (1959). The logic of scientific discovery (author, Trans.). New York: Basic Books.

Quine, W. V. O. (1948). Two dogmas of empiricism. Philosophical Review, 60, 20-43.

Reid, W. (1994a). The empirical practice movement. Social Service Review 68(2) 165-184.

Reid, W. J. (1994b). Reframing the epistemological debate. In E. Sherman \& W. J. Reid (Eds.). Qualitative research in social work. New York: Columbia University Press.

Royse, D. R. (1999). Research methods in social work. Chicago: Nelson Hall.

Rubin, A. \& Babbie, E. (2001). Research methods for social work (4th edition). Belmont, CA, Wadsworth.

Saleebey, D. (1979). The tension between research and practice: Assumptions of the experimental paradigm. Clinical Social Work Journal, 7, 267-284.

Saleebey, D. (1989). The estrangement of knowing and doing: Professions in crisis. Social Casework, 70, 556-563.

Saleebey, D. (1994). Culture, theory, and narrative: The intersection of meanings in practice. Social Work, 39, 351-359.

Salmon, W. (1971). Statistical explanation and statistical relevance. Pittsburgh, PA: University of Pittsburgh Press.

Salmon, W. (1989). Four decades of scientific explanation. Minneapolis, MN: University of Minnesota Press.

Salomon, E. (1967). Humanistic values and social casework. Social Casework, 48, 26-32. 
Schuerman, J. (1982). The obsolete scientific imperative in social work research. Social Service Review, 56, 144-146.

Schuerman, J. (1987). Passion, analysis, and technology: The Social Service Review Lecture. Social Service Review 61: 3-18.

Scriven, M. (1969). Logical positivism and the behavioral sciences. In P. Achinstein \& S. Barker (Eds.), The legacy of logical positivism: Studies in the philosophy of science. Baltimore: Johns Hopkins University Press.

Simon, H. (1966). Scientific discovery and the psychology of problem solving. In R. Colodny (Ed.). Mind and cosmos. Pittsburgh, PA: University of Pittsburgh Press.

Social Work Research Group. (1955). The function and practice of research in social work. Unpublished reports with introduction by Margaret Blenkner: Research Section, National Association of Social Workers.

Sperry, R. (1983). Science and moral priority: Merging mind, brain, and human values. New York: Columbia University Press.

Suppe, F. (Ed.). (1977). The structure of scientific theories, 2nd edition. Urbana, IL: University of Illinois Press.

Task Force on Social Work Research. (1991). Building social work knowledge for effective services and policies: A plan for research development. Austin, TX: Capital Printing.

Thyer, B. (1989). First principles of practice research. British Journal of Social Work, 19, 309-323.

Thyer, B. (1991). Guidelines for evaluating outcome studies on social work practice. Research on Social Work Practice, 1, 76-91.

Thyer, B. (1993). Social work theory and practice research: The approach of logical positivism. Social Work and Social Sciences Review 4(1), 5-26.

Thyer, B. (2001). What is the role of theory in research on social work practice? Journal of Social Work Education 37, 9-25.

Thyer, B. \& Myers, L. (1998). Supporting the client's right to effective treatment: Touching a raw nerve? Social Work 43, 87-91.

Thyer, B. \& Myers, L. (1999). On science, antiscience, and the client's right to effective treatment. Social Work 44, 501-508.

Tyson, K. (1992). A new approach to relevant and scientific research for practitioners: The heuristic paradigm. Social Work, 37, $541-556$.

Tyson, K. (1994a). Author's reply: Response to "Social work researchers' quest for respectability.” Social Work, 39, 737-741.

Tyson, K. (1994b). Heuristic guidelines for naturalistic qualitative evaluations of child treatment. In E. Sherman \& W. J. Reid (Eds.), Qualitative research in social work. New York: Columbia University Press.

Tyson, K. (1994c). Response to 'Randomized controlled trials in the human services.' Social Work Research, 18, 61-62.

Tyson, K. (1995). New foundations for scientific social and behavioral research: The heuristic paradigm. Needham Heights, MA: Allyn \& Bacon.

Tyson, K. (1999). An empowering approach to crisis intervention and brief treatment for preschool children. Families in Society, 80, 64-77.

Tyson, K. (2000). Using the teacher-student relationship to help children diagnosed as hyperactive. Child and Youth Care Forum, 29, 265-289.

Tyson, K., \& Carroll, E. (2001). Innovative, therapeutic care for homeless, mentally ill clients: Intrapsychic humanism in a residential setting. Families in Society, 82, 591-603.

Vigilante, J. (1974). Between values and science: Education for the profession during a moral crisis or is proof truth? Journal of $\mathrm{So}_{0}$ cial Work Education, 10, 107-115.
Wainstock, S. (1994). Swimming against the current: Teaching research methodology to reluctant social work students. Journal of Teaching in Social Work, 9 (1/2), 3-16.

Wallace, W. (1971). The logic of science in sociology. Chicago, AldineAtherton.

Weick, A. (1991). The place of science in social work. Journal of Sociology and Social Welfare, 18, 13-34.

Weick, A. (1992). Should scholarly productivity be the primary criterion for tenure decisions? No! Journal of Social Work Education, $28,135-138$.

Williams, M., Unrau, Y., \& Grinnell, R. (1998). Introduction to Social Work Research. Itasca, IL: F. E. Peacock.

Wimsatt, W. C. (1981). Robustness, reliability, and overdetermination. In M. Brewer \& B. Collins (Eds.). Scientific inquiry and the social sciences. San Francisco: Jossey-Bass.

Wimsatt, W. C. (1986). Heuristics and the study of human behavior. In D. W. Fiske and R. A. Shweder (Eds.), Metatheory in social science: Pluralisms and subjectivities. (pp. 293-314). Chicago: University of Chicago Press.

Wimsatt, W. C. (1987). False models as means to truer theories. In M. H. Nitecki \& A. Hoffman (Eds.), Neutral models in biology (pp. 23-55). New York: Oxford University Press.

Witkin, S. L. (1993). A human rights approach to social work research and evaluation. In J. Laird (Ed.), Revisioning Social Work Education: A Social Constructionist Approach. (pp. 239-254). Binghamton, N.Y.: Haworth Press.

Witkin, S. L. (1995). Making social work scientific: Analysis and recommendations. In K. Tyson (Ed.). New foundations for scientific social and behavioral research: The heuristic paradigm. Needham Heights, MA: Allyn \& Bacon.

Witkin, S. (1998). Mirror, mirror on the wall: Creative tensions, the academy, and the field. Social Work, 43, 389-391.

\section{Jessica Heineman-Pieper is a doctoral student, University of Chicago departments of Psychology and the Conceptual Foundations of Science, 400 E. Randolph Street, \#1990, Chicago, IL 6060; e-mail: jhpieper@uchicago.edu. Katherine Tyson is professor, Loyola University of Chicago School of Social Work, 820 N. Michigan Ave., Chicago, IL, 60611. Martha Heineman Pieper is in private practice, 400 E. Randolph St., Suite 205, Chicago, IL, 60601.}

Manuscript received: September 28, 2000

Revised: November 30, 2001

Accepted: December 10, 2001 